\title{
Trimeric and hexameric calixarene-based capsules
}

\author{
Wanda Śliwa* and Barbara Dondela \\ Institute of Chemistry and Environmental Protection, Jan Dtugosz University, \\ al. Armii Krajowej 13/15, 42-201 Częstochowa, Poland \\ E-mail:w.sliwa@ajd.czest.pl
}

\begin{abstract}
In this paper trimeric and hexameric capsules are presented. In the first section trimeric calixarene-based capsules are described, they are followed by trimeric cavitand-based capsules. In the second section hexameric resorcinarene-based capsules are characterized; moreover two examples of covalently bound hexameric cavitand-based capsules are shown.
\end{abstract}

Keywords: Cavitand, hydrogen bond, inclusion complex, receptor, resorcinarene

\section{Table of Contents}

Introduction

1. Trimeric capsules

2. Hexameric capsules

Conclusions

References

\section{Introduction}

Calixarene-based capsules are a topic of numerous reports; so dimeric capsules ${ }^{1-5}$ as well as species of higher multiplicity ${ }^{6-9}$ are intensively studied due to their interesting properties and application possibilities. Calixarene-based capsules of higher multiplicity are mainly trimeric and hexameric species, albeit tetrameric and octameric compounds are also known. ${ }^{10,11}$ An attention is paid now to nanotubes, ${ }^{12,13}$ this theme however is not described here.

The present review is a continuation of our paper dealing with dimeric capsules ${ }^{14}$; our previous works concern cavitands, ${ }^{15-17}$ calixarenes as metal ion receptors ${ }^{18,19}$ as well as resorcinarenes ${ }^{20}$ and calixpyrroles. ${ }^{21}$

The efficient synthesis of capsules which are large enough to entrap various guests is a great challenge. ${ }^{11,22-25}$ Capsules are held together by weak noncovalent interactions, such as hydrogen 
bonding or by metal-coordination. Multivalent recognition of building blocks requires a sufficient number of recognition sites. An advantageous feature of such self-assembled structures is that they are mostly formed under thermodynamically controlled conditions.

Capsules are receptors that completely surround their guests, in this way isolating them from the bulk. ${ }^{26}$ Capsules are promising as nanoreactors ${ }^{27}$ in which intermediates are stabilized ${ }^{28}$ as well as probe materials for weak interactions; ${ }^{26,29}$ moreover they are useful in separation technologies ${ }^{30}$ and nanodevices fabrication. ${ }^{31}$

In the present review we describe trimeric and hexameric capsules showing their syntheses and properties. In the first part selected examples of trimeric capsules are presented, they are followed by hexameric species. The references are cited mainly from reports that have appeared since 2005 .

\section{Trimeric capsules}

Trimeric capsules, i.e. trimers consisting of three calixarene or cavitand units are held together by weak noncovalent interactions. First, the examples of calixarene-based trimeric capsules will be presented, followed by examples of cavitand based trimeric capsules.

In the study of trimeric capsules, ${ }^{6}$ calix[4]arenes 1-4 functionalized with alkyl (1), aminoalkyl (2), ureido (3) and pyridyl (4) moieties have been synthesized. ${ }^{32}$ Self-assembly of 1-4 with barbituric acid and cyanuric acid derivatives, $\mathbf{B}$ and $\mathbf{C}$, respectively, in methanolchloroform mixtures affords trimeric capsules 5 and 6. Trimeric capsule, i.e. double rosette consists of two rosette motifs, top and bottom ones, which are connected via three calixarene units. One rosette contains 18 hydrogen bonds, whereas double rosette contains 36 hydrogen bonds. Trimeric capsules 5, and $\mathbf{6}$ are stable in apolar solvents, e.g. benzene, toluene and chloroform; increase in the solvent polarity results in their destabilization .

The introduced functionalities affect the thermodynamic stability of $\mathbf{5}$, and $\mathbf{6}$. For example, hydrogen bond donating or accepting groups interfere with the existing hydrogen bonding, and bulky groups cause a steric hindrance decreasing the thermodynamic stability of $\mathbf{5}$, and $\mathbf{6}$. It was observed that $\mathbf{5}$, and $\mathbf{6}$ containing $n$-alkyl groups are more stable than those bearing more polar aminoalkyl or pyridyl groups. The stability of $\mathbf{5}$, and $\mathbf{6}$ decreases in the order of alkyl groups present: 1a $>1 \mathbf{b}>\mathbf{1 c}$ since their increased branching results in a higher steric hindrance.

It should be pointed out that the stability of $\mathbf{5}$, and $\mathbf{6}$ containing ureido groups is the highest as compared to those bearing $n$-alkyl, aminoalkyl and pyridyl functionalities due to the formation of extra hydrogen bonds of ureido groups with the triazine units. 


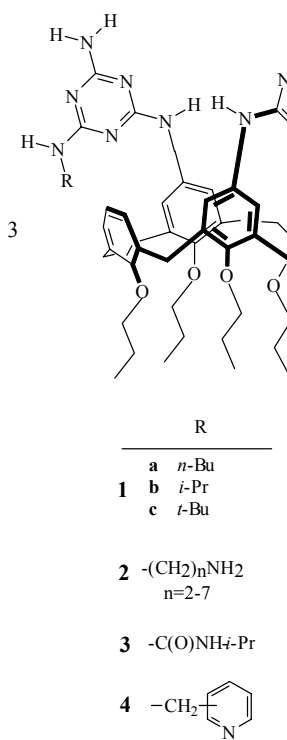

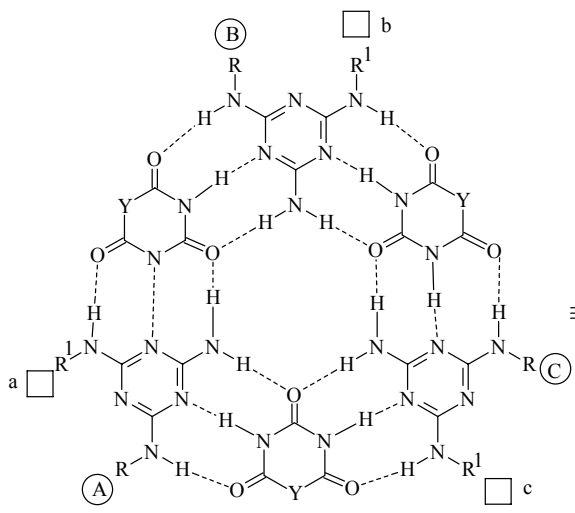

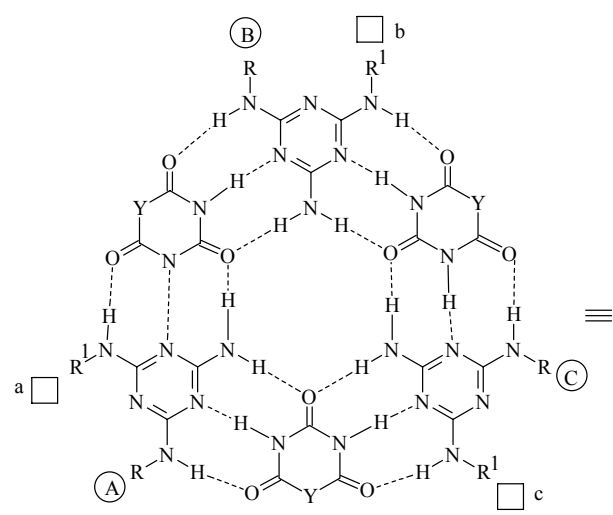

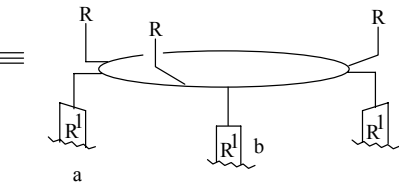

top rosette 18 hydrogen bonds

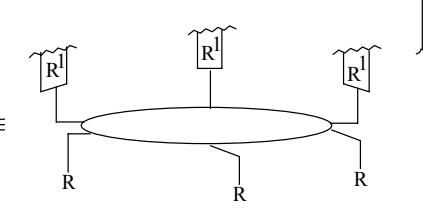

bottom rosette

18 hydrogen bonds

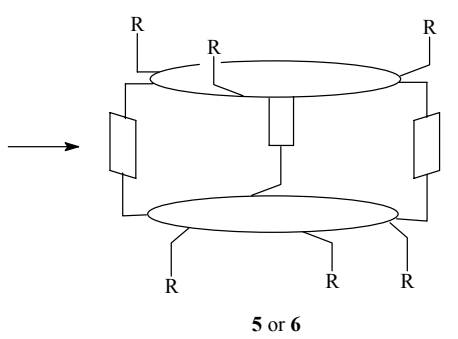

double rosette $=$ trimeric capsule 36 hydrogen bonds 
The self-assembly via hydrogen-bond formation is useful for preparation of liquid-crystalline materials. ${ }^{33,34}$ It was observed that calix[4]arene $\mathbf{7}$ and $\mathbf{B}$ or $\mathbf{C}$ self-assemble spontaneously upon mixing in apolar solvent to give the mesogenic trimeric capsules $\mathbf{7}_{\mathbf{3}} \cdot \mathbf{B}_{\mathbf{6}}$ or $\mathbf{7}_{\mathbf{3}} \cdot \mathbf{C}_{\mathbf{6}}$ which are thermodynamically stable. The trimeric capsule $\mathbf{7}_{\mathbf{3}} \cdot \mathbf{B}_{\mathbf{6}}$ shows lower thermal stability than $\mathbf{7}_{\mathbf{3}} \cdot$ $\mathbf{C}_{6}$, since melamine forms weaker hydrogen bonds with barbiturates than with cyanurates.

The melamine units of 7 are functionalized with octadecyl groups to promote the selforganization of the trimeric capsules into a liquid-crystalline phase. The long substituents of benzamide moieties of 7 prevent their interference with hydrogen bonding network which holds the double rosette together.

The trimeric capsules form columns, which assemble into columnar liquid-crystalline mesophases of a high degree of order and of a considerable thermal stability. It is noteworthy that the liquid-crystalline phase is observed for the trimeric capsule assemblies, even though none of the isolated building components is mesogenic. The driving force for the self-assembly of columns is the nanoscale segregation of the double rosette cores and the lipophilic alkyl chains.

It was found that the reaction of calixarenes 8-10 with $\mathbf{C}$ affords trimeric capsules 11 which may confine phenols $\mathbf{1 2}$, carboxylic acids 13 and carbohydrate derivative $\mathbf{1 4}$ serving as guests. ${ }^{35}$

Trimeric capsules $\mathbf{1 1}$ are exo-receptors since their recognition sites are situated at the periphery, i.e. at the top and the bottom of the receptor; the encapsulation of six guest molecules affords inclusion complexes 15. The melamine units of trimeric capsules $\mathbf{1 1}$ bear ureido, amino and L- serine moieties to recognize phenols 12 a-c, carboxylic acids 13 a-c and carbohydrate derivative 14, respectively. The complexation was studied by ${ }^{1} \mathrm{H}$ NMR spectroscopy and ITC (isothermal titration calorimetry).

The complexation of calixarene 8 with $p$-nitrophenol 12a shows a 1:6 binding mode; single hydrogen bonding exists between all six ureido carbonyl groups of $\mathbf{8}$ and hydroxyl groups of 12a; with 12b and 12c however the 1:3 binding mode was observed: each guest molecule forms two hydrogen bonds with two urea moieties at the top and the bottom rosette of 11.

The complexation of calixarene 9 with carboxylic acids 13a-c shows the 1:6 binding mode; inclusion of these guests involves hydrogen bonding between amino groups of the receptor and carboxylic groups of the guests. The complexation of $\mathbf{1 0}$ with $n$-octylgalactopyranoside $\mathbf{1 4}$ involves the formation of hydrogen bonds between the serine hydroxyl groups of the receptor and hydroxyl groups of the guest 14. 


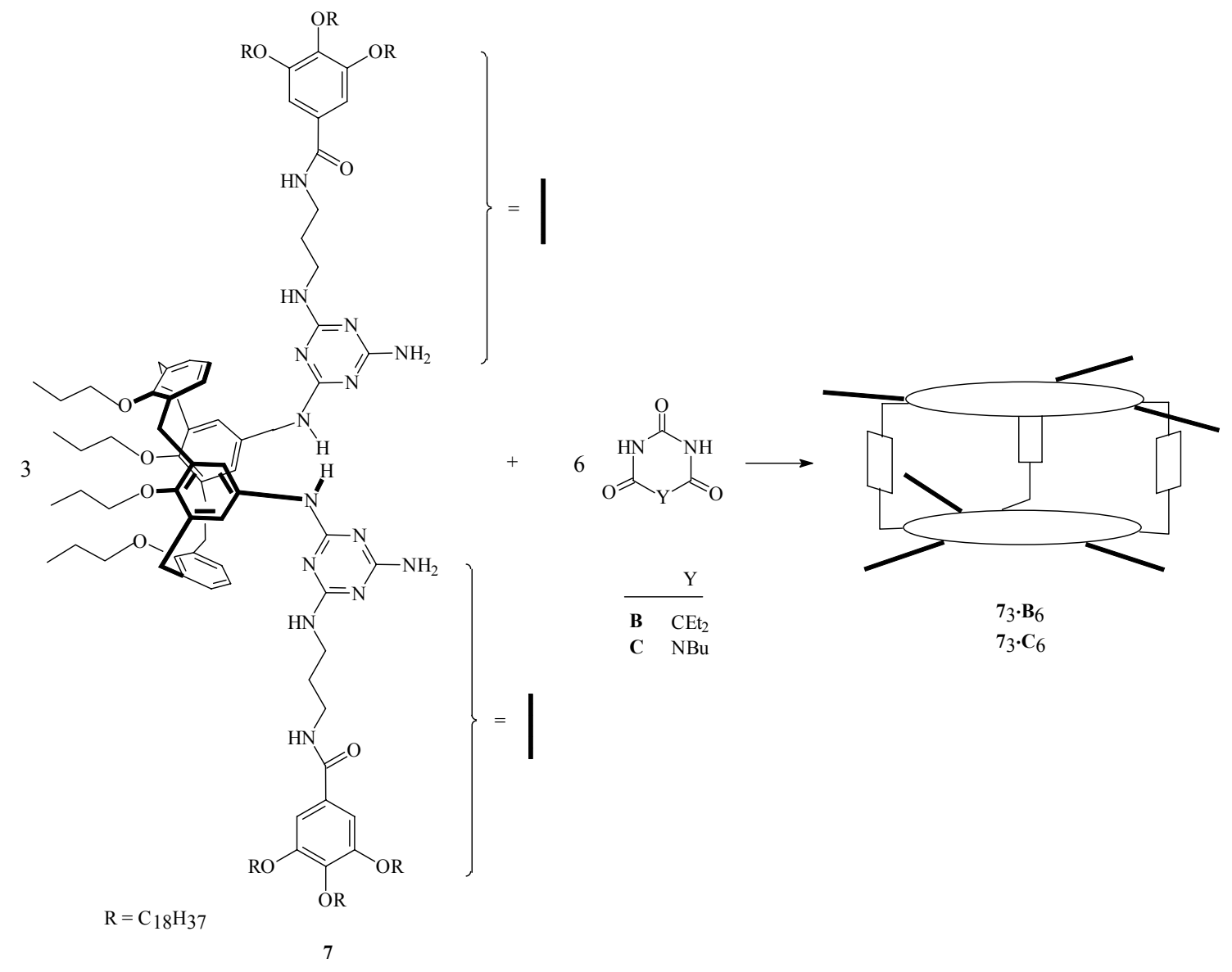

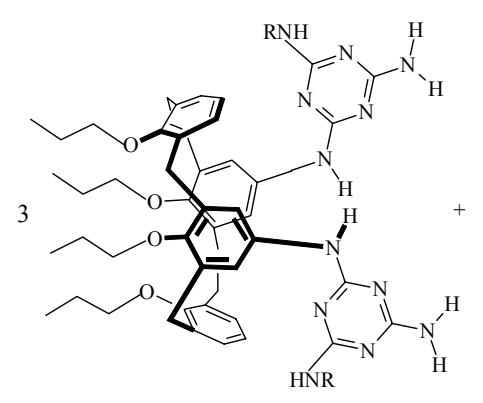

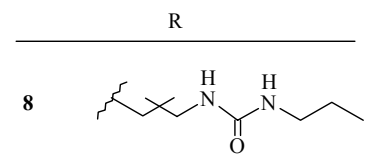

$9 \quad \times \mathrm{NH}^{2}$

10 等

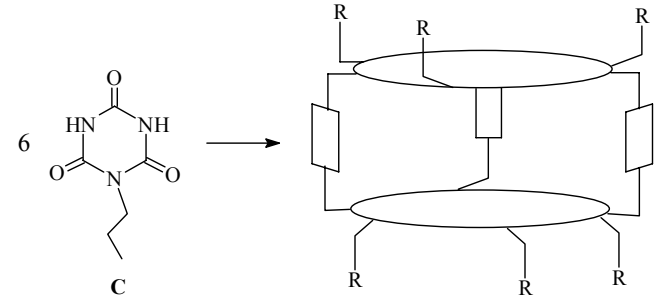

11

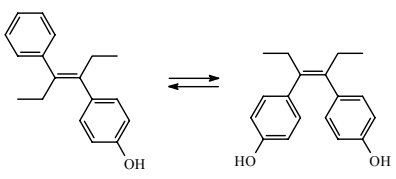

12b

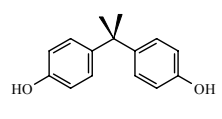

12a

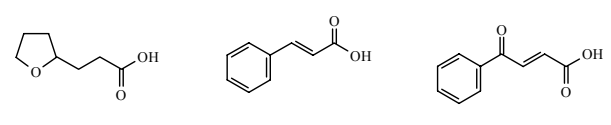

$13 \mathrm{c}$

$13 \mathrm{~b}$

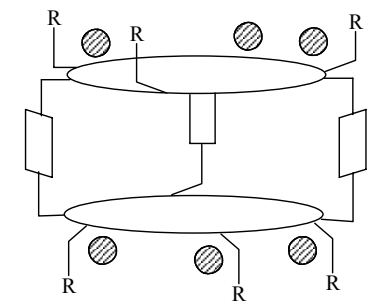

15

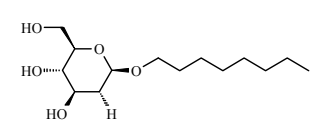

14 


\section{Scheme 2}

The reaction of calixarenes $\mathbf{1}$ and 16-18 with $\mathbf{B}$ yields trimeric capsules 19; their complexation with hydrogen bonded trimers of anthraquinone derivatives 20-25 serving as guests was investigated. ${ }^{36}$ The driving force for the encapsulation of guest trimers leading to inclusion complexes $\mathbf{2 6}$ is the $\pi-\pi$ stacking between melamine units of the host and the central ring of anthraquinone derivatives.

Trimeric capsules 19 and hydrogen-bonded alizarin trimer $\mathbf{2 0}_{3}$ form the inclusion complexes in which alizarin trimer $\mathbf{2 0}_{3}$ is encapsulated between the two rosette layers. The complexation of trimers of $\mathbf{2 1}$ and of $\mathbf{2 2}$ occurs in a similar way. It was observed that the presence of the carbonyl groups in the central ring and the presence of at least one hydroxyl group in the anthraquinone molecule are necessary for complexation. For this reason anthracene $\mathbf{2 3}$ and anthraquinone $\mathbf{2 4}$ do not form complexes; in the case of anthracene $\mathbf{2 3}$ both carbonyl and hydroxyl groups are lacking, and in anthraquinone $\mathbf{2 4}$ the hydroxyl groups are lacking. It should be noted that derivative $\mathbf{2 5}$ cannot be encapsulated due to steric reasons.

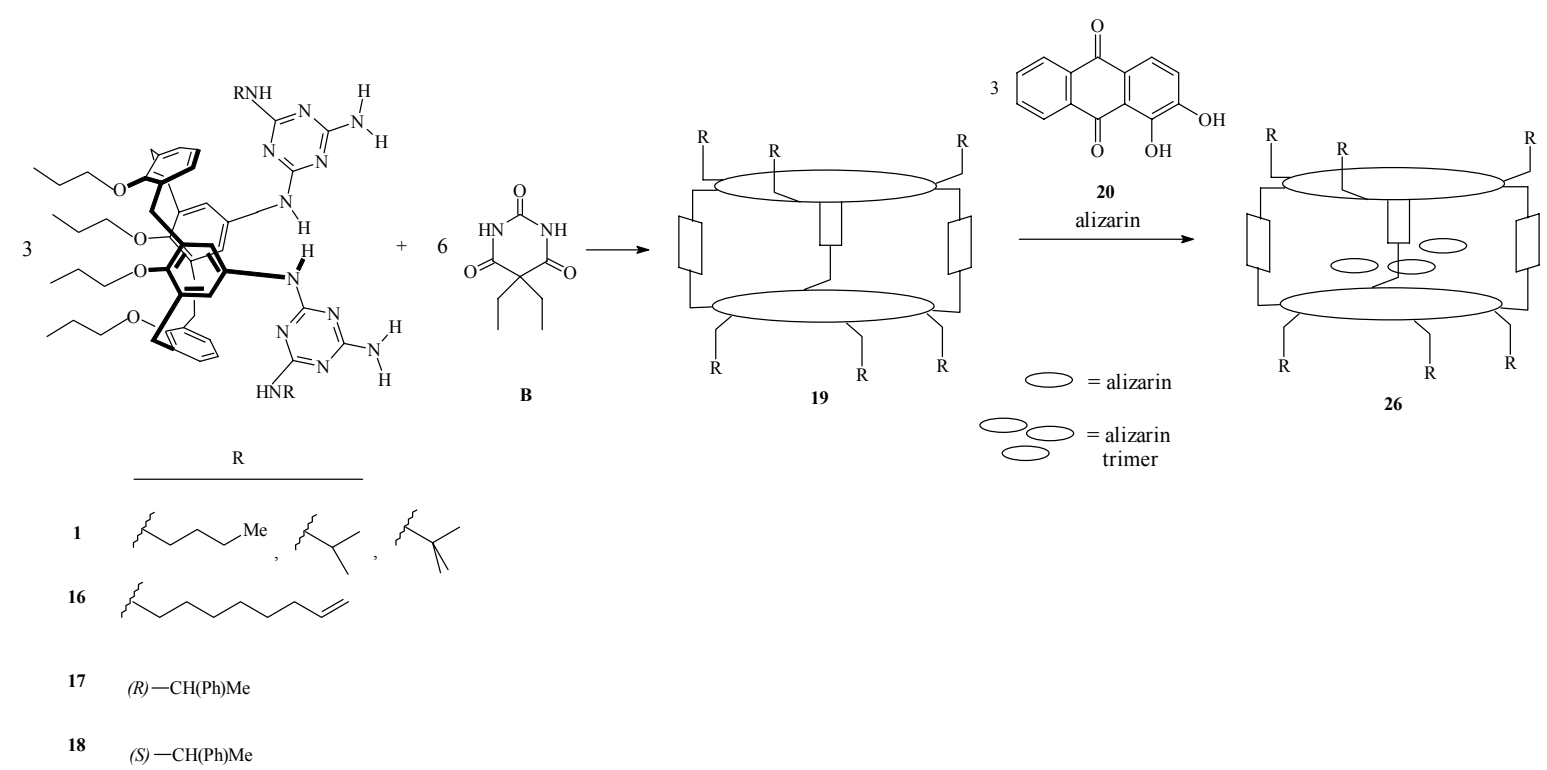




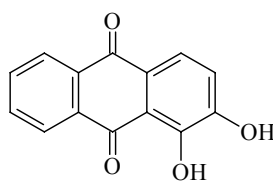

20

alizarin

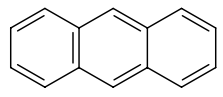

23

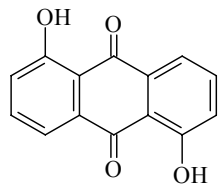

21

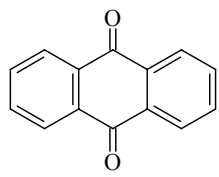

24

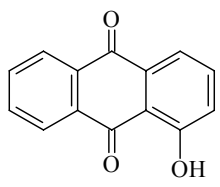

22

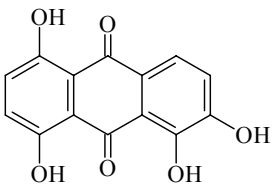

25

\section{Scheme 3}

It was found that dimeric calixarene $27 \mathbf{a}, \mathbf{b}$ consisting of two calix[4]arene units linked by the $\mathbf{Z}$ spacer reacts with $\mathbf{B}$ to give tetrarosette $\mathbf{2 8}$ formed from two double rosettes linked by three Z spacers. ${ }^{37}$

Barbiturate-based tetrarosettes $27_{3} \cdot \mathbf{B}_{12}$ i.e. 28 are spontaneously formed in apolar solvents such as benzene, toluene or chloroform when $\mathbf{2 7}$ is mixed with twelve equivalents of $\mathbf{B}$ at room temperature. The driving force for this self-assembly is the formation of 72 hydrogen bonds, i.e. 18 hydrogen bonds for each rosette. The above self-assembly process results in the formation of tetrarosettes with high kinetic stability; the dissociation of tetrarosette requires the disruption of 24 hydrogen bonds.

Cyananurate based tetrarosettes $\mathbf{3 7}_{\mathbf{3}} \cdot \mathbf{C}_{\mathbf{1 2}}$ have been obtained by two methods: by mixing 37 and $\mathbf{C}$ derivatives in toluene and heating to $100{ }^{\circ} \mathrm{C}$ for one week (direct method) or by treatment of $\mathbf{3 7}$ with $\mathbf{B}$ and subsequent exchange by $\mathbf{C}$ derivatives (exchange method).

The amplification of chirality of tetrarosettes was investigated under thermodynamically controlled conditions. In the study of double rosettes ${ }^{38}$ it was established that an important factor for the amplification of chirality is the dissociation rate of calixarenes 1. A lower dissociation rate constant leads to higher amplification of chirality, i.e. a larger optical activity with lower amounts of chiral component.

Tetrarosettes consist of two double rosettes. The dissociation of one dimeric calixarene 27 from tetrarosette requires the disruption of 24 hydrogen bonds, i.e. the dissociation rate constant is lower as compared to a double rosette, in which dissociation of one calixarene 1 unit requires disruption of only 12 hydrogen bonds. Therefore a higher amplification of chirality occurs in the case of a tetrarosette.

The difference in free energy between the $\mathrm{M}$ and $\mathrm{P}$ diastereomers of the tetrarosettes introduced by a chiral center is higher than in the case of double rosettes. This difference results from the lower dissociation rate constant of the calixarene $\mathbf{2 7}$ units than in the case of calixarene 1 units. 
The extent of the chiral amplification depends on the structure of the tetrarosette; when the bisureido spacer of tetrarosette $\mathbf{2 8 a}$ was replaced by the more rigid $m$-xylene spacer to give tetrarosette $\mathbf{2 8 b}$ the amplification of chirality considerably decreased due to steric hindrance resulting from the presence of the rigid spacer. It was established that the degree of chiral amplification of the tetrarosette is not influenced by the method of its formation (direct or exchange method).

Tetrarosette 28a $\cdot \mathbf{B}_{\mathbf{1 2}}$ undergoes complexation with six molecules of alizarin $\mathbf{2 0}$ in the form of two trimers which are hydrogen bonded; they are intercalated inside both double rosettes to give inclusion complex 29. ${ }^{39}$ Upon encapsulation large conformational changes in the host structure occur. It should be pointed out that the intercalation is highly selective.

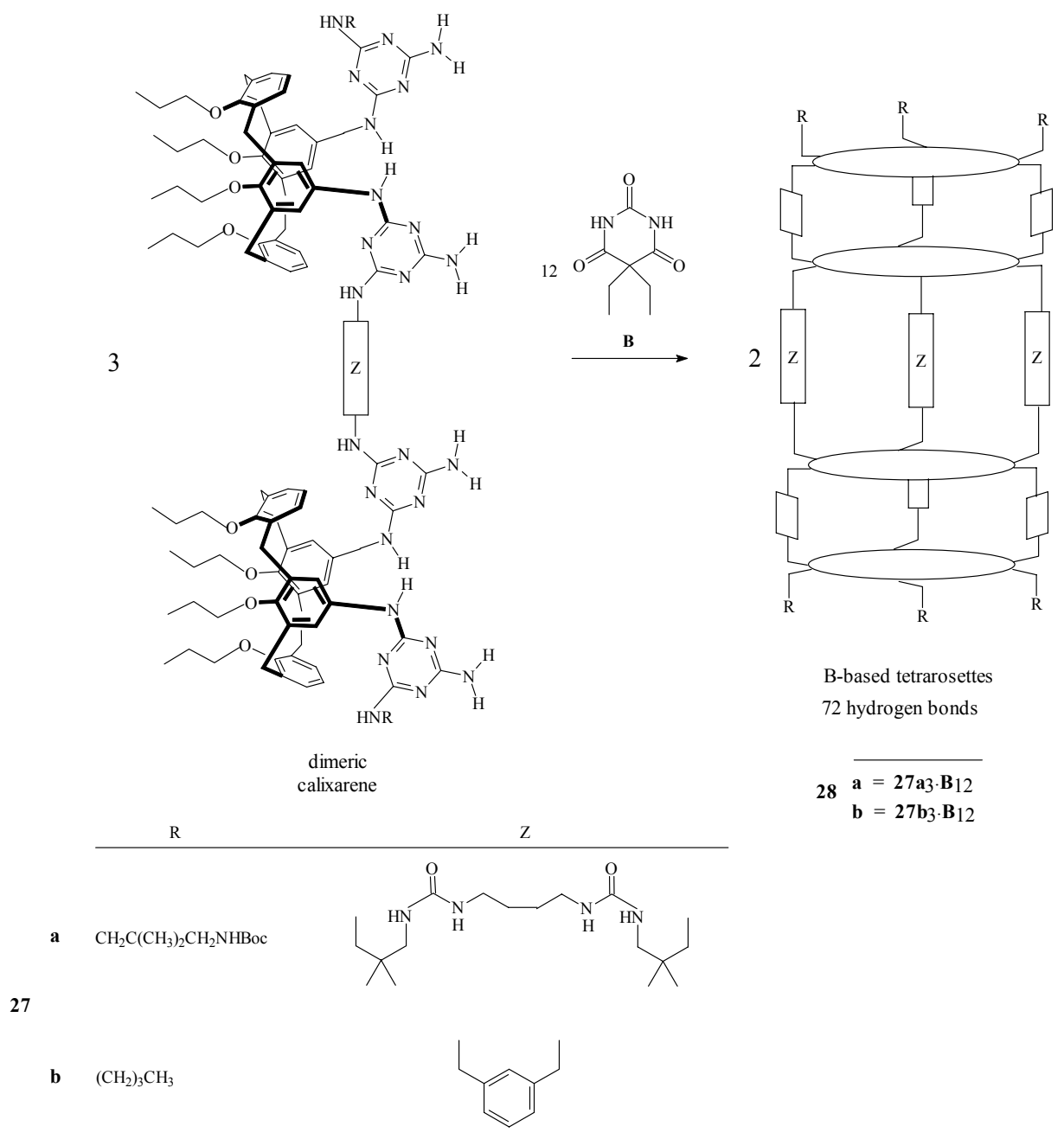



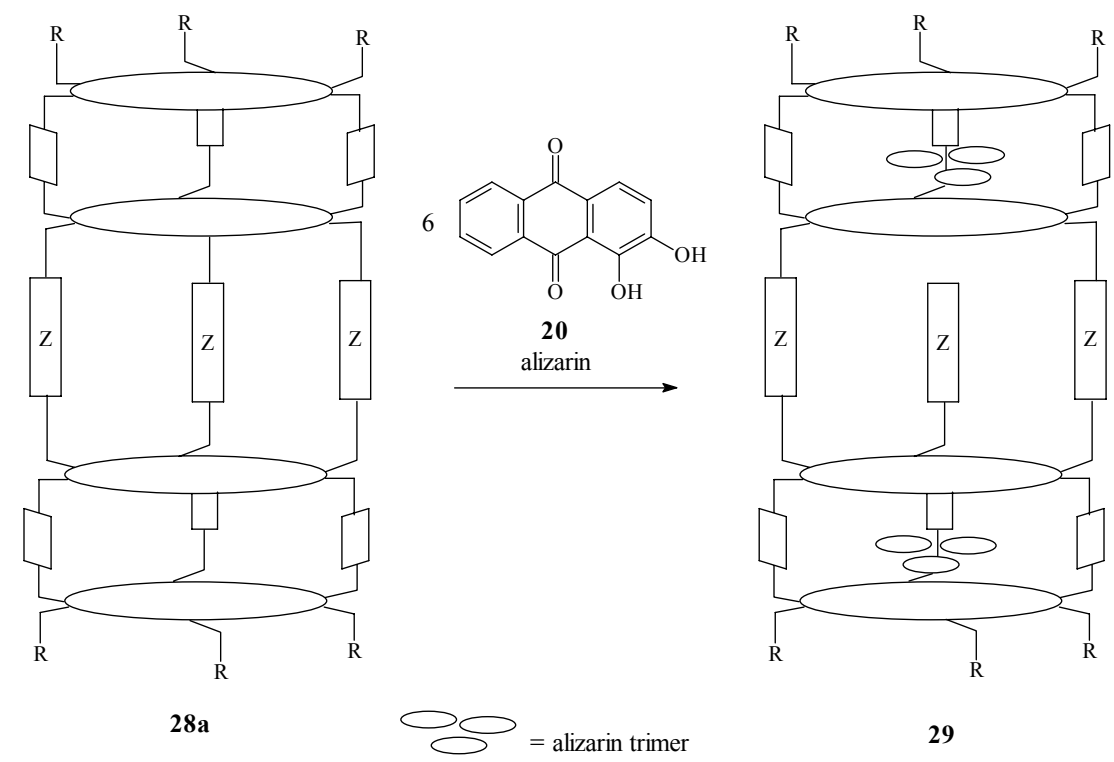

\section{Scheme 4}

Metal-directed self-assembly is an efficient method for the construction of large, three- dimensional supramolecular structures ${ }^{40,41}$ which may encapsulate guest molecules and catalyze chemical reactions proceeding inside their cavities ${ }^{42}$; among them the metal-bound cavitand assemblies have been intensively studied. ${ }^{43-45}$

It was established that the self-assembly of rigid cavitands $\mathbf{3 0}$ and $\mathbf{3 1}$ with platinum complex 32 affords platinum coordinated trimeric capsules 33 and $34{ }^{46}$ These supramolecular platinum complexes were characterized by ${ }^{1} \mathrm{H}$ and ${ }^{31} \mathrm{P}$ NMR spectroscopy and electrospray ionization mass spectrometry.

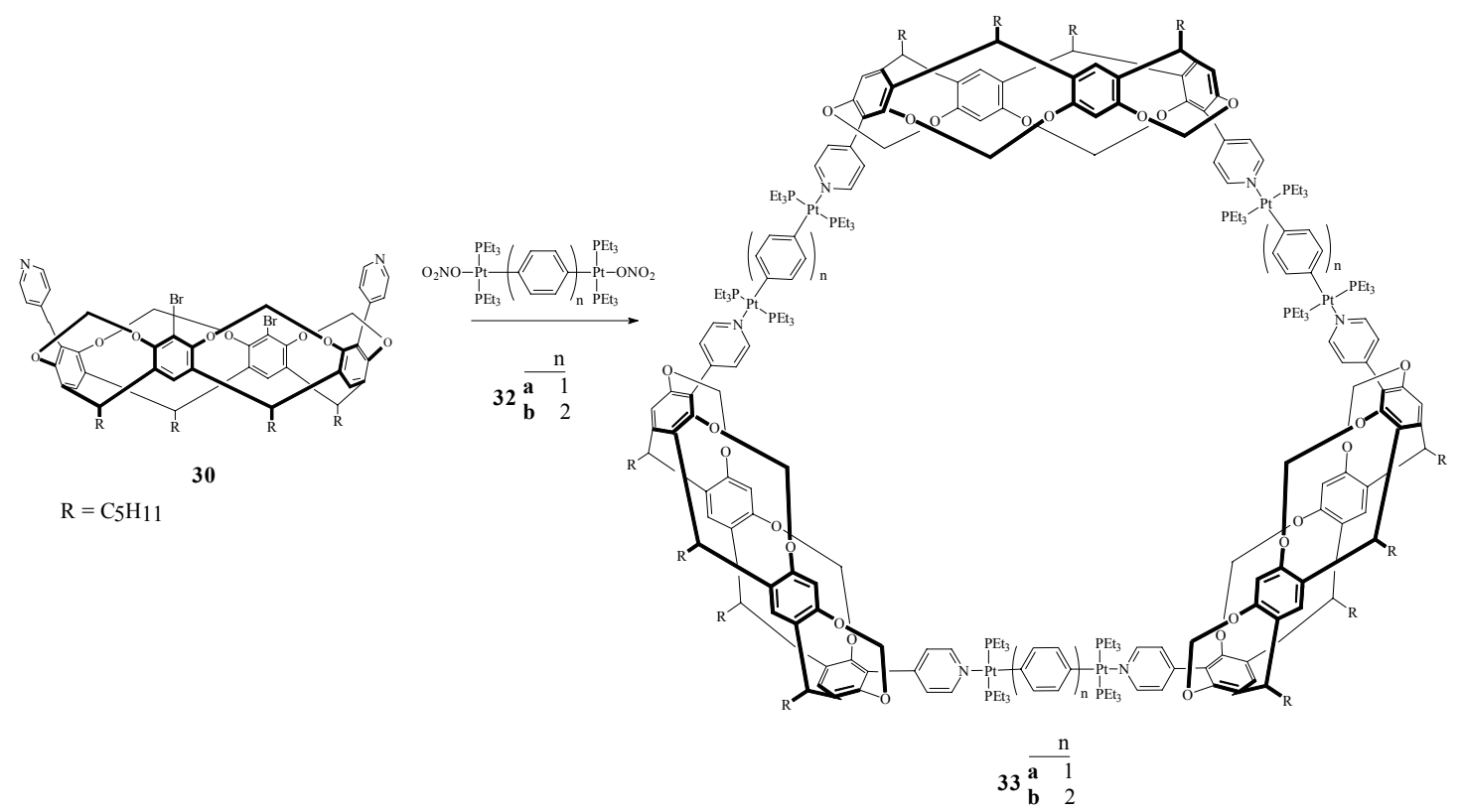




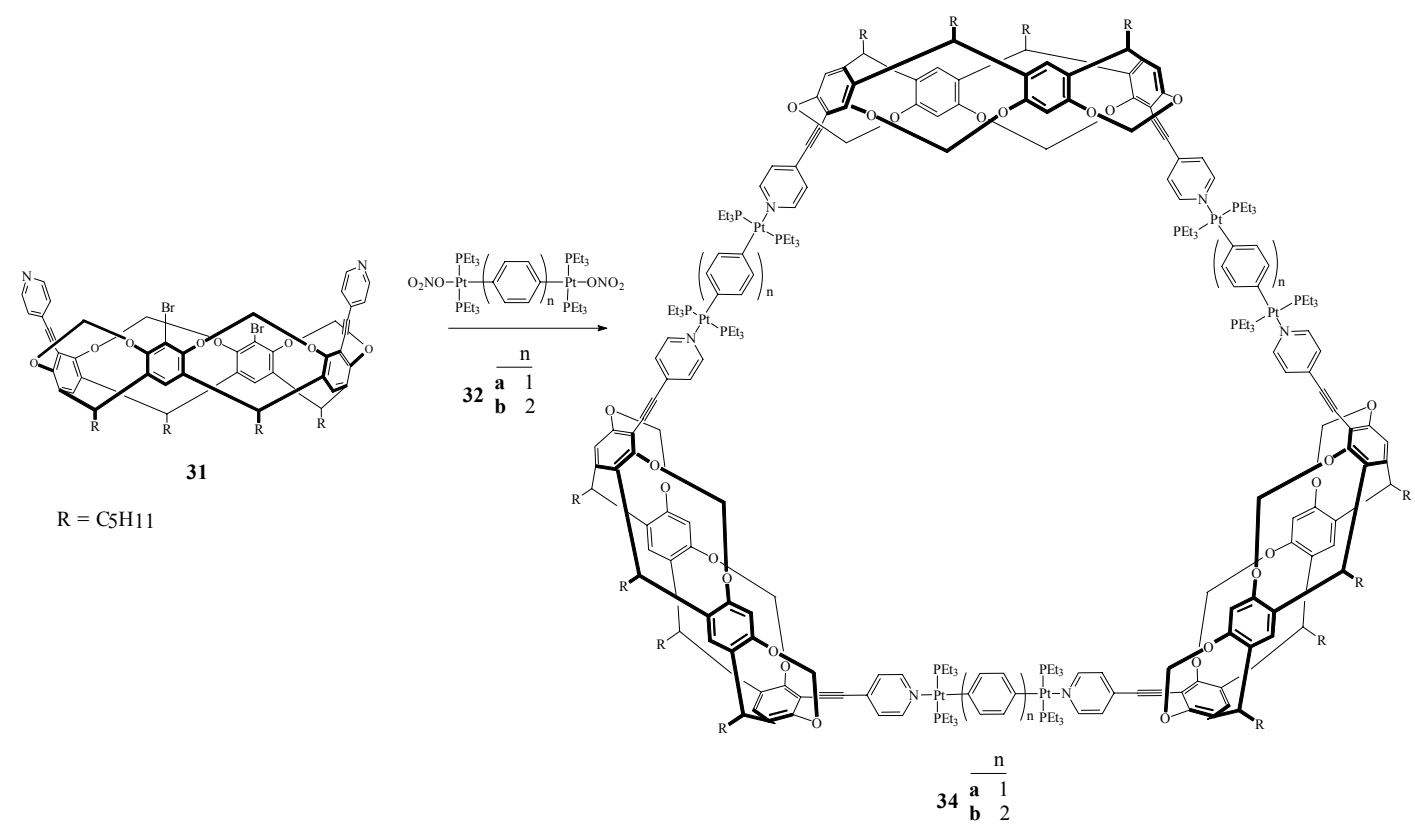

Scheme 5

One should also mention cavitand-based polymetallic assemblies containing $\mathrm{Zn}(\mathrm{II}), \mathrm{Cd}(\mathrm{II})$, $\mathrm{Cu}(\mathrm{II}), \mathrm{Au}(\mathrm{II}), \mathrm{Ni}(\mathrm{II})$ and $\mathrm{Pd}(\mathrm{II})$ ions; in these compounds the cavitand structures are functionalized with dithiocarbamate units. In dependence on stereochemical coordination preference of metals, the trimeric or tetrameric capsules 35 or 36, respectively, are formed. In the case of zinc (II) and cadmium (II) the trimeric capsules 35a-f are obtained, while for copper (II), gold (II), nickel (II) and palladium (II) the tetrameric capsules are formed; ${ }^{47}$ the formulas of $\mathrm{Cu}(\mathrm{II})$ tetrameric capsules $\mathbf{3 6 a}-\mathbf{c}$ are shown.

Both types of capsules form strong inclusion complexes with fullerenes $\mathrm{C}_{60}$ and $\mathrm{C}_{70}$; the cadmium capsule has proven to be the most suitable receptor for fullerenes. The strong binding of the above capsules with fullerenes results from the interaction of fullerenes with sulfur atoms of multiple dithiocarbamate moieties of the host systems. 


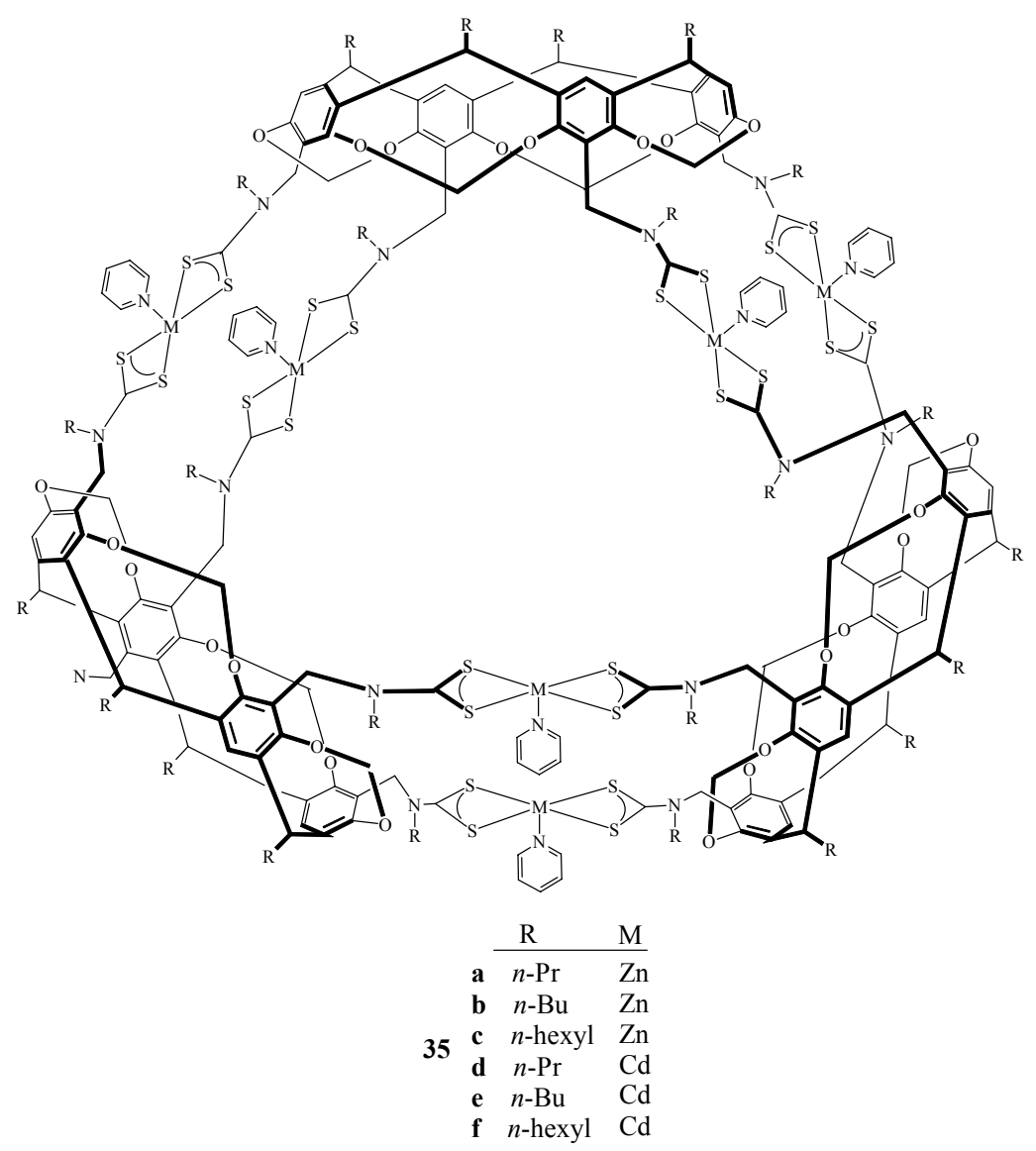




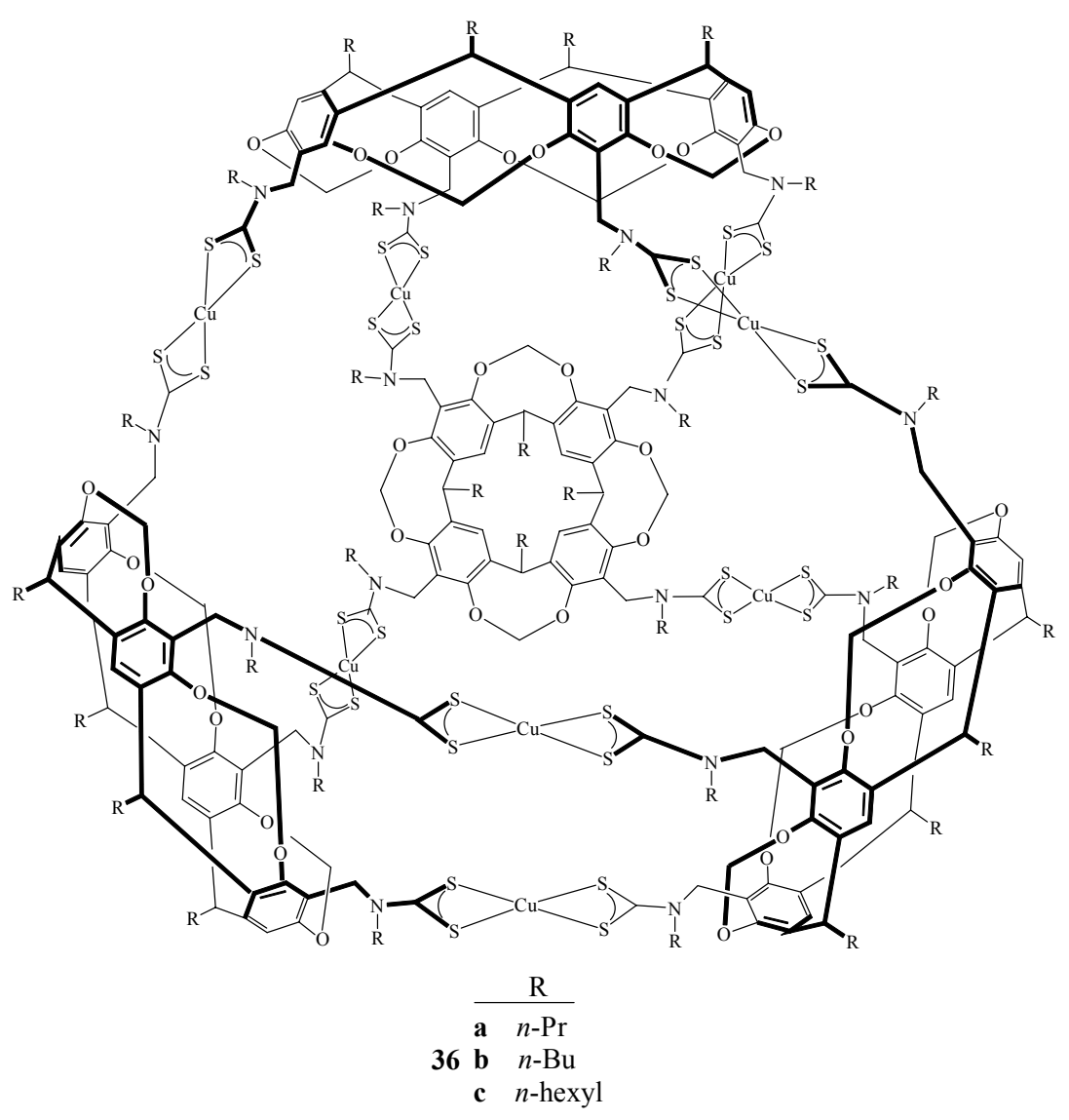

\section{Scheme 6}

\section{Hexameric capsules}

The synthesis of large spheroid capsules able to entrap different guest molecules is an important topic in supramolecular chemistry. ${ }^{26}$ The methods of their construction mainly involve selfassembly via hydrogen bonds or metal coordination. ${ }^{25}$ The bowl-shaped resorcin[4] arene and pyrogallol[4]arene macrocycles form large hexameric capsules, i.e. hexamers, by hydrogen bonding. Substitution of hydrogen atoms for metal ions results in structural preservation of hexameric structure, while introducing inorganic functionality.

In the study of hexameric capsules their guest affinity, tautomeric equilibria and isotope effects ${ }^{7,8,26}$ were examined. It should be pointed out that the investigation of dimeric cylindrical capsules $^{14}$ is more detailed than that of hexameric capsules of resorcinarenes and pyrogallolarenes.

Resorcinarene- and pyrogallolarene-based hexameric capsules are held together by hydrogen bonding. ${ }^{26,48-50}$ It should be pointed out that pyrogallol[4]arenes contain four additional upper rim hydroxyl groups, as compared with resorcinarenes; this fact results in a larger number of 
hydrogen-bonding interactions in formed hexamers and, as a consequence, the higher stability than in the case of resorcinarene-based hexameric capsules. ${ }^{50,51}$

Resorcinarenes and pyrogallolarenes form hexameric capsules in the solid state and in solution via a network of hydrogen bonds. Usually water molecules are involved to complete the hydrogen bond network of resorcinarene-based hexameric capsules, ${ }^{49}$ while assembly of pyrogallolarenes does not require water molecules. In hexameric capsules solvent molecules often serve as guests. ${ }^{48,52}$

First the hexamers formed from resorcinarenes and pyrogallolarenes are described, they are followed by two examples of covalently bound hexamers obtained from cavitands.

In the study of guests exchange it was established that capsules act as mechanical barriers between guest and the bulk solution; for formation of a suitable opening for guest release the rupture of multiple hydrogen bonds is necessary.

Resorcinarene $\mathbf{3 7}$ forms in the presence of trialkylammonium salts $\mathbf{3 8}$ in water-saturated $\mathrm{CDCl}_{3}$ the hexameric capsule $37_{6}$ incorporating one $\mathbf{3 8}^{+} \mathrm{Br}^{-}$molecule. The remaining space in the hexamer cavity is occupied by coencapsulated solvent molecules, their number decreasing with the cation size of $\mathbf{3 8}^{+} \mathrm{Br}^{-}$. The guest exchange requires the dissociation of one resorcinarene molecule from the hexamer.

It was observed that $\mathbf{3 8} \mathrm{a}^{+} \mathrm{Br}^{-}$and $\mathbf{3 8} \mathrm{b}^{+} \mathrm{Br}^{-}$share the cavity with three chloroform molecules, however in the case of $\mathbf{3 8 \mathbf { c } ^ { + }} \mathrm{Br}^{-}$and $\mathbf{3 8 \mathbf { d } ^ { + }} \mathrm{Br}^{-}$only two $\mathrm{CHCl}_{3}$ molecules are coencapsulated, while $\mathbf{3 8}^{+} \mathrm{Br}^{-}$and $\mathbf{3 8 f}^{+} \mathrm{Br}^{-}$leave place merely for one $\mathrm{CHCl}_{3}$ molecule. The stability of considered inclusion complexes decreases in the case of larger cations and is anion-dependent, for example

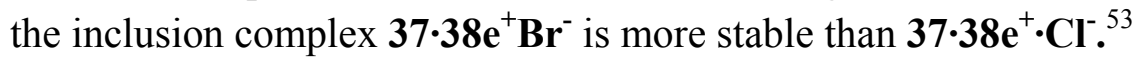

In investigation of inclusion complexes of hexamer $\mathbf{3 7} 6$ with glutaric acid 39, with 1,2-ciscyclohexanediol 40 and with L-phenylalanine 41, the in-out guest exchange rate constants were determined by an exchange (EXSY) NMR spectroscopy ${ }^{54}$. The resorcinarene $\mathbf{3 7}$ and an appropriate guest, or more than one guest in wet solvents is all that is required for formation of the hexameric capsule. The proper filling of space is of importance; optimal guests fill about half the available cavity themselves or together with additional solvent molecules. The hexamer $\mathbf{3 7}_{\mathbf{6}}$ may confine even three different guests.

Resorcinarenes $\mathbf{4 2}$ form hexamers $\mathbf{4 2} \mathbf{2}_{6} \cdot\left(\mathrm{H}_{2} \mathrm{O}\right)_{8}$ held together by an array of hydrogen bonds. It was found that the water molecules in $\mathbf{4 2}_{\mathbf{6}} \cdot\left(\mathrm{H}_{2} \mathrm{O}\right)_{8}$ may be replaced by alcohols, such as $( \pm)$ 2ethylhexanol (EH). ${ }^{55}$

Resorcinarene 42a was crystallized from EH. It was observed that the crystals of 42a grown by evaporation from EH afford hexamer $\mathbf{4 2}_{6} \cdot(\mathrm{EH})_{6}\left(\mathrm{H}_{2} \mathrm{O}\right)_{2}$, in which three molecules of $\mathrm{EH}$ are included. The difference between $\mathbf{4 2 \mathbf { a } _ { 6 }} \cdot\left(\mathrm{H}_{2} \mathrm{O}\right)_{8}$ and $\mathbf{4 2} \mathbf{a}_{\mathbf{6}}(\mathrm{EH})_{6}\left(\mathrm{H}_{2} \mathrm{O}\right)_{2}$ is the fact that $\mathbf{4 2 \mathbf { a } _ { 6 }} \cdot\left(\mathrm{H}_{2} \mathrm{O}\right)_{8}$ is chiral, whereas $\mathbf{4 2} \mathbf{a}_{6}(\mathrm{EH})_{6}\left(\mathrm{H}_{2} \mathrm{O}\right)_{2}$ is achiral.

The replacement of some number $x$ of the eight water molecules from $\mathbf{4 2}_{\mathbf{6}} \cdot\left(\mathrm{H}_{2} \mathrm{O}\right)_{8}$ by EH molecules affords $\mathbf{4 2} \mathbf{b}_{6} \cdot(\mathrm{EH})_{\mathrm{x}} \cdot\left(\mathrm{H}_{2} \mathrm{O}\right)_{8-\mathrm{x}}$ along with $\mathrm{x}$ liberated water molecules. It should be pointed out that the all eight molecules of water cannot be completely expelled by EH from $\mathbf{4 2}_{6} \cdot(\mathrm{EH})_{\mathrm{x}} \cdot\left(\mathrm{H}_{2} \mathrm{O}\right)_{8-\mathrm{x}} \cdot{ }^{55}$ 
It was observed that pyrogallolarene $\mathbf{4 3}$ undergoes a spontaneous self-assembly to give hexameric capsule $\mathbf{4 3}_{6}{ }^{56}$ For the solvent- free synthesis of $\mathbf{4 3}$ the dispersion of pyrrogallol and a catalytic amount of solid $p$-toluenesulfonic acid was treated with aldehyde and milled using a mortar and a pestle; this solvent-free procedure yields pyrogallol[4]arene 43. The self-assembly of $\mathbf{4 3}$ affords hexameric capsule $\mathbf{4 3}$.

Pyrogallol[4]arene 44 forms the hexamer $\mathbf{4 4}_{6}$ of a large cavity which can serve as a nanoreactor; the behavior of solvent molecules within the cavity of $\mathbf{4 4}_{\mathbf{6}}$ was investigated by different NMR techniques. ${ }^{52}$

It was found that 6-7 molecules of chloroform are enclosed in this hexamer. Using a mixture of benzene with chloroform as a solvent one could expect that at least some hexameric capsules $\mathbf{4 4}_{6}$ should contain only benzene or only chloroform, however it was not the case. The results of ${ }^{1} \mathrm{H}$ NMR spectroscopy have not indicated the presence of hexamer $\mathbf{4 4}_{\mathbf{6}}$ enclosing only benzene, or only $\mathrm{CHCl}_{3}$, even in the presence of a large excess of benzene or $\mathrm{CHCl}_{3}$, respectively. It was shown that the benzene and chloroform co-encapsulation is preferred and that the larger molecular fraction of the so-called benzene / chloroform complex in $\mathbf{4 4}_{\mathbf{6}}$ as compared with the bulk is indicated by a strong ASIS (aromatic solvent-induced shift) effect. ${ }^{52}$

Resorcinarenes $\mathbf{4 5}$ and pyrogallolarene $\mathbf{4 6}$ form hexameric capsules. In the case of $\mathbf{4 5}$ the six resorcinarene units assemble with eight structural water molecules to give the near-spherical hexamer $\mathbf{4 5}_{6}$, held by hydrogen bonding. In the case of pyrogallolarene $\mathbf{4 6}$, the formed hexamer $\mathbf{4 6}_{6}$ has more hydrogen bonds than $\mathbf{4 5}_{\mathbf{6}}$, therefore is more stable; it cannot assemble with water molecules. $^{57}$

The anthracene derivative $\mathbf{4 7}$ was used as a fluorescent probe molecule for inclusion into hexamer $\mathbf{4 6}_{\mathbf{6}}$. It was observed that $\mathbf{4 7}$ crystallizes endo or exo to the $\mathbf{4 6}_{\mathbf{6}}$ framework, the former mode being more frequent. In the case of endo-crystallization 47 is encapsulated in the hexamer; in the case of exo-crystallization the molecules of $\mathbf{4 7}$ intercalate between walls of neighboring hexameric capsules. Both crystallization modes result in highly different fluorescence emission, the fluorescence emission intensity of $\mathbf{4 7}$ in the case of endo-crystallisation being higher than for the free $47 .{ }^{57}$ 

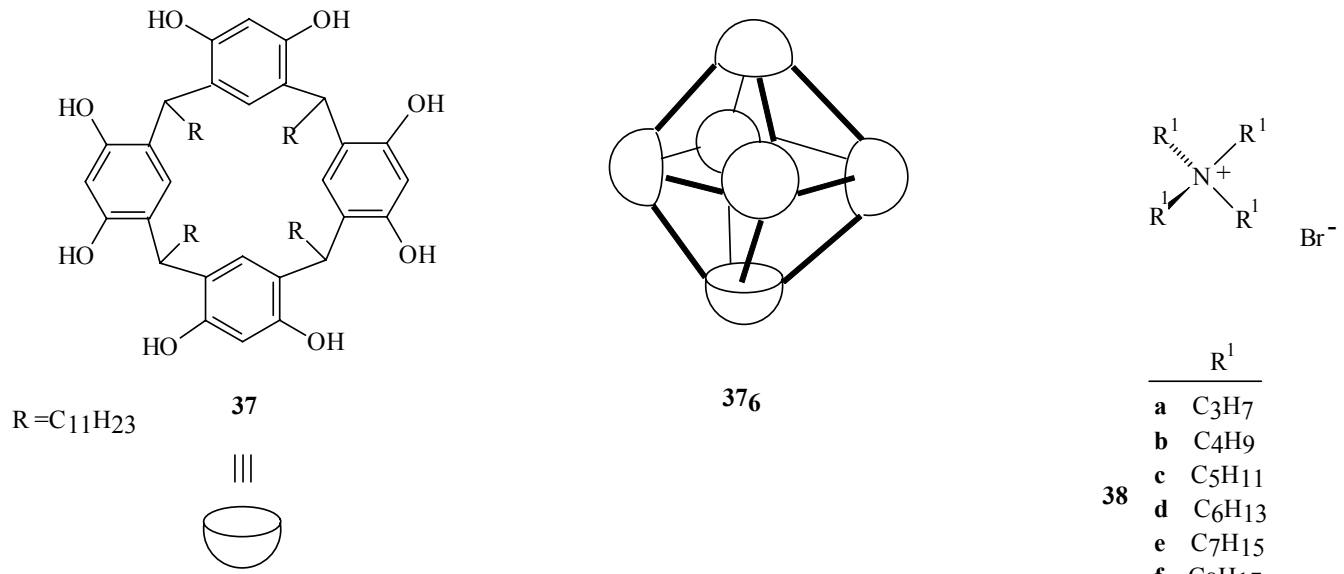

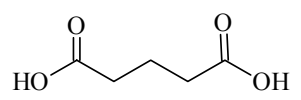

39

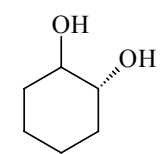

40

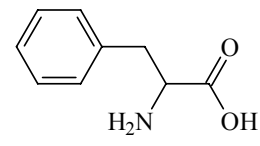

41

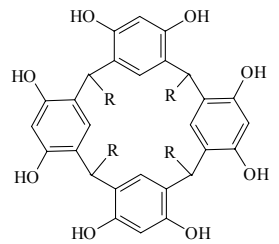

$\begin{array}{ll}\frac{\mathrm{R}}{\mathbf{4}} \mathrm{a} & \mathrm{Me} \\ \mathbf{b} & \mathrm{C} 11 \mathrm{H}_{23}\end{array}$

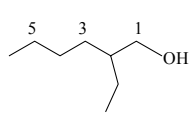

EH

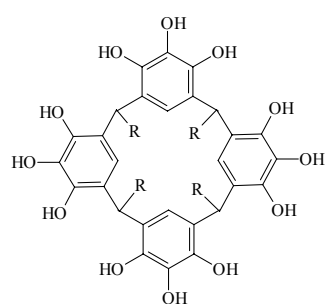

$\frac{\mathrm{R}}{43 \mathrm{CH}_{2} \mathrm{CH}\left(\mathrm{CH}_{3}\right)_{2}}$

$44 \mathrm{C}_{11} \mathrm{H}_{23}$

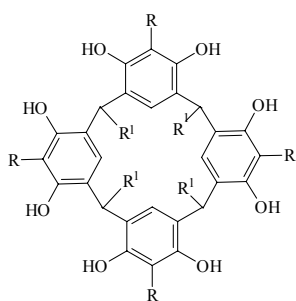

\begin{tabular}{lll} 
& $\mathrm{R}$ & $\mathrm{R}^{1}$ \\
\hline 45 & $\mathrm{H}$ & $\mathrm{Me}$
\end{tabular}

46 OH 6 $6 \mathrm{H}_{13}$

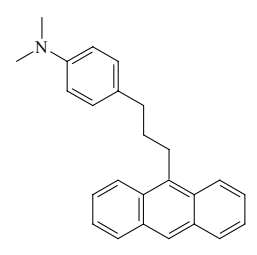

47

\section{Scheme 7}

Formation of hexameric capsules from resorcinarenes 48, 49 and pyrogallolarene $\mathbf{5 0}$ has been investigated using MS methods. Cationic guests may template the capsule formation, as those 51-53 have been used. ${ }^{58}$

It was observed that the size, shape and symmetry of cationic guests serving as templates are very important in formation of hexameric capsules; the template properties of used cations decrease in the order $\mathbf{5 3}>\mathbf{5 2}>\mathbf{5 1}$ showing that $\mathbf{5 1}$ is too small for cavity of hexamers. In the case of 51 the dimeric capsule $\mathbf{5 1 \cdot 5 0 _ { 2 }}$ and in the case of $\mathbf{5 2}$ the hexameric capsule $\mathbf{5 2 \cdot 5 0 _ { 6 }}$ are formed. Modeling studies on the basis of X-ray crystallography for $[\mathbf{5 3 \cdot 5 0}]^{\mathbf{2}}$ have shown that $\mathbf{5 3}$ fits very well into the cavity of hexamer $\mathbf{5 0}_{\mathbf{6}}$. In this hexamer the periphery of a pyridine ring of $\mathbf{5 3}$ is 
directed towards each of the six molecules of pyrogallolarene 50. The hexameric capsules formed from resorcinarenes 48, 49 and from pyrogallolarene 50 retain their structure even in the gas phase and do not rearrange during ionization indicating the stabilizing influence of suitable templating cationic guests. ${ }^{58}$

Resorcinarenes and pyrogallol[4]arenes may form large spherical, metal coordinated hexamers in both solution and solid state. It should be pointed out that among metal coordinated capsules the dimeric capsules are more common than the larger ones.

It was found that the treatment of pyrogallolarene 54 with $\mathrm{Cu}\left(\mathrm{NO}_{3}\right)_{2} \cdot 3 \mathrm{H}_{2} \mathrm{O}$ in a mixture of acetone and water leads to the metal-directed self-assembly affording large neutral hexameric coordination capsule 55 i.e. $\left[\mathrm{Cu}_{24}\left(\mathrm{H}_{2} \mathrm{O}\right)_{\mathrm{x}}\left(\mathrm{C}_{40} \mathrm{H}_{40} \mathrm{O}_{16}\right)_{6} \subset(\text { acetone })_{n}\right] ;(\mathrm{n}=1-6) .{ }^{59}$ The formed hexamer 55 held together by eight planar $\left[\mathrm{Cu}_{3} \mathrm{O}_{3}\right]$ arrays $\mathbf{5 6}$ is structurally analogous to hydrogen-bonded solid-state hexamer 57 containing 24 chelate sites.

Hexamer 55 consists of six pyrogallol[4] arene ligands and $24 \mathrm{Cu}$ (II) ions. Insertion of $24 \mathrm{Cu}$ (II) ions into the hydrogen-bonded hexameric capsule 57 results in substitution of 48 protons. The remaining 24 phenol groups participate in hydrogen bonding. In 55 no counterions are necessary, since the positive charge of $\mathrm{Cu}$ (II) ions is counterbalanced by protonated phenol groups.

The hexamer $\mathbf{5 5}$ is held together by combination of metal-ligand coordination and of hydrogen bonding; it may be viewed as an octahedron 58 in which eight faces are capped by 8 six-membered $\left[\mathrm{Cu}_{3} \mathrm{O}_{3}\right]$ arrays. The hexamer 55 preserves the structural framework of hydrogen bonded hexamer $\mathbf{5 7}$ and has similar dimensions. This structural preservation enables the interchangeability of a desired function; the hydrogen-bonded hexamers are preferred when reversible encapsulation is necessary, whereas metal coordinated ones are more rigid and stable.

It should be pointed out that 24 hydroxyl groups localized at the periphery of $\mathbf{5 5}$ can act as recognition sites. In the solid state, these periphery hydroxyl groups connect to adjacent hexameric capsules $\mathbf{5 5}$ via copper-hydroxyl coordination. ${ }^{59}$

It was found that treatment of pyrogallol[4]arene 59 with $\mathrm{Ga}\left(\mathrm{NO}_{3}\right)_{3} \cdot \mathrm{H}_{2} \mathrm{O}$ in a mixture of acetone and water results in a self-assembly affording large metal- coordinated hexameric capsule 60, i.e. $\left.\mathrm{Ga}_{12}\left(\mathrm{H}_{2} \mathrm{O}\right)_{24}\left(\mathrm{C}_{40} \mathrm{H}_{42} \mathrm{O}_{12}\right)_{6} \subset(\text { acetone })_{8}\left(\mathrm{H}_{2} \mathrm{O}\right)_{6}\right]$ held together by four slightly curved $\left[\mathrm{Ga}_{3} \mathrm{O}_{3}\right]$ arrays $\mathbf{6 1}$, situated on four faces of octahedron. ${ }^{60}$

The results of X-ray analysis show that $\mathbf{6 0}$ consists of 18 components: 6 pyrogallol[4] arene ligands and $12 \mathrm{Ga}$ (III) ions and has a ,rugby ball” shape.

It should be noted that in the analogous hexameric capsules 55 each of eight octahedral faces is capped by $\left[\mathrm{Cu}_{3} \mathrm{O}_{3}\right]$ array, in contrast to $\mathbf{6 0}$ in which only four octahedral faces are capped by $\left[\mathrm{Ga}_{3} \mathrm{O}_{3}\right]$ arrays. Due to this difference in the number of capping $\left[\mathrm{Ga}_{3} \mathrm{O}_{3}\right]$ and $\left[\mathrm{Cu}_{3} \mathrm{O}_{3}\right]$ arrays, the hexamer $\mathbf{6 0}$ has only 20, while the hexamer 55 has 24 intramolecular hydrogen bonds. The absence of four hydrogen bonds in $\mathbf{6 0}$ as compared to 55 results in its more flexible structure than that of 55; this flexible structure is responsible of rugby ball topology of 60 , while 55 has a spherical shape. 


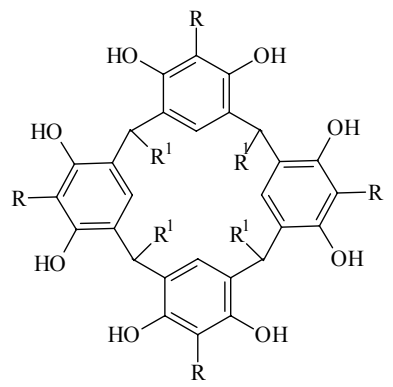

\begin{tabular}{lll} 
& $\mathrm{R}$ & $\mathrm{R}^{1}$ \\
\hline $\mathbf{4 8}$ & $\mathrm{H}$ & $\mathrm{Et}$ \\
$\mathbf{4 9}$ & $\mathrm{H}$ & $\mathrm{Pr}$ \\
$\mathbf{5 0}$ & $\mathrm{OH}$ & $\mathrm{Pr}$
\end{tabular}

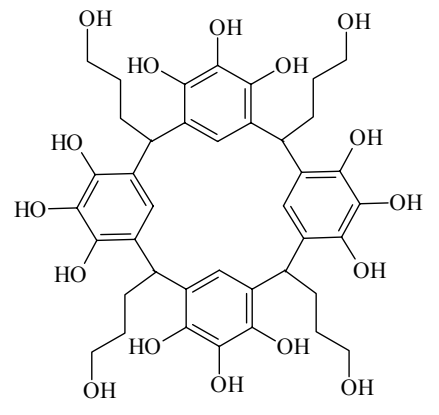

54

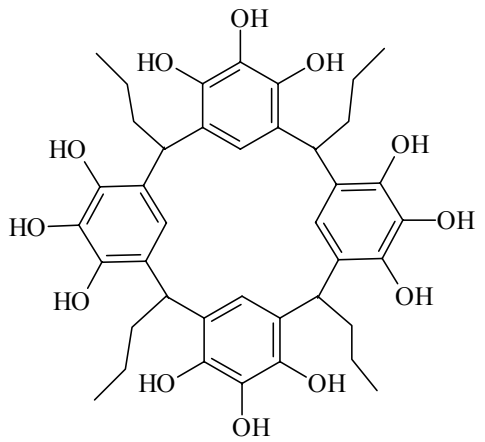

59

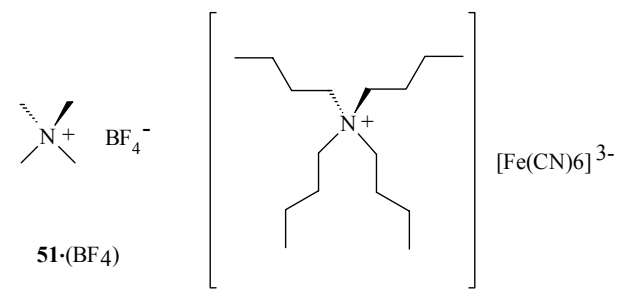

(52) $3\left[\mathrm{Fe}(\mathrm{CN})_{6}\right]$

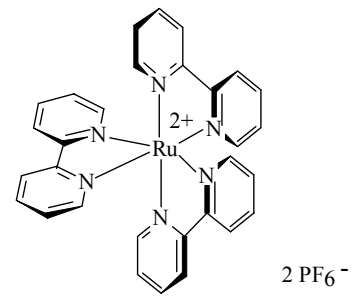

$53\left(\mathrm{PF}_{6}\right)_{2}$

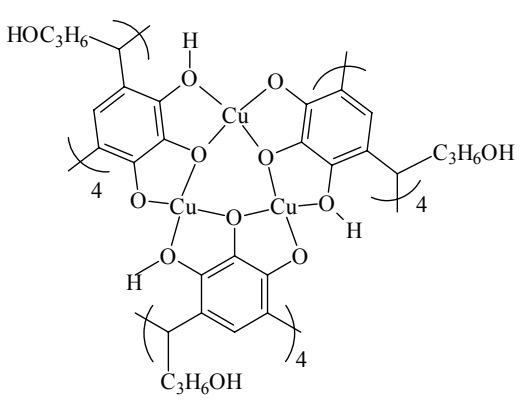

56

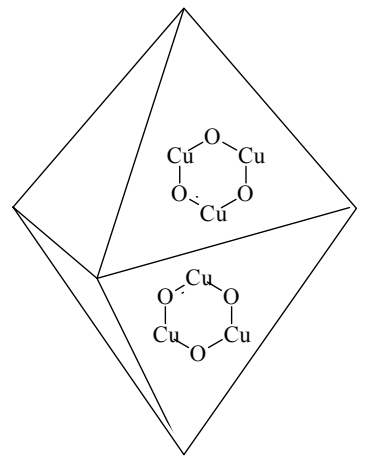

58

\section{Scheme 8}

The two next examples concern covalent capsules obtained by dynamic covalent chemistry. It is noteworthy that dynamic covalent chemistry is very convenient for syntheses of complex molecules. ${ }^{61-63}$ 
In the first example the cavitand $\mathbf{6 2}$ derived from pyrogallolarene was a starting material. The benzylation of two adjacent hydroxyl groups of $\mathbf{6 2}$ leads to cavitand $\mathbf{6 3}$. The subsequent cyclization of 63 with bromochloromethane affords hexabenzylated trimer 64, which was debenzylated by hydrogenation to give hexahydroxyl trimer $\mathbf{6 5}$. The bridging of $\mathbf{6 5}$ with bromochloromethane in the presence of DMSO yields hexameric capsule incorporating seven DMSO molecules as guests, i.e. 66.(DMSO) $)_{7}{ }^{64}$ It should be pointed out that this is a very large carceplex which is a covalent analogue of noncovalently bound pyrogallolarene hexamers.

The NMR data and MM2 calculations indicate that 66•(DMSO $)_{7}$ has a slightly flattened, non symmetric structure; it reversibly complexes water molecules to give $\mathbf{6 6} \cdot(\mathrm{DMSO})_{7} \cdot\left(\mathrm{H}_{2} \mathrm{O}\right)_{\mathrm{x}}$; $\mathrm{x}$ is not known. The host may entrap larger guests (e.g. DMSO) permanently and smaller guests (e.g. $\mathrm{H}_{2} \mathrm{O}$ ) temporarily. Carceplex $66 \cdot(\text { guest })_{7}$ shows a permanent entrapment of the largest number of guests for such a container. The formation of this carceplex is driven by a seven- guest template effect. The high selectivity for statistically unfavored seven molecule templates over templates with other molecularities involves the binding of one guest by each of the six bowls; in the centre of the formed cavity is a place for the seventh guest molecule.

Template ratios for competing seven-molecule templates in the formation of 66 (DMSO $)_{\mathrm{x}}$. $\mathrm{G}_{(7-\mathrm{x})}$ for reactions in DMSO/G ( $\mathrm{G}=\mathrm{DMF}$ or DMA) were evaluated. The high selectivity of DMSO over DMF or DMA was found. For 66. (DMSO) $)_{x} \cdot G_{(7-x)}$ the templating ability for seven-molecule templates increases with the number of encapsulated DMSO molecules; carceplexes with four or more DMF or DMA molecules were not even observed. It should be pointed out that for such a large container, and for guests of similar shape and polarity, this selectivity is very high. ${ }^{64}$

In the second example the tetraformyl cavitand 67 was a starting material. It was observed that one-pot reactions of $\mathbf{6 7}$ with ethylene 1,2-diamine $\mathbf{6 8}$ lead to covalently bound capsules of a different shape, in dependence on the kind of solvent; in THF the tetramer 69 , in $\mathrm{CHCl}_{3}$ the hexamer 70 and in $\mathrm{CH}_{2} \mathrm{Cl}_{2}$ the octamer $\mathbf{7 1}$ are formed ${ }^{10,11}$. Octamer $\mathbf{7 1}$ is a square antiprismatic capsule in which each cavitand occupies one of the eight corners ${ }^{11}$.

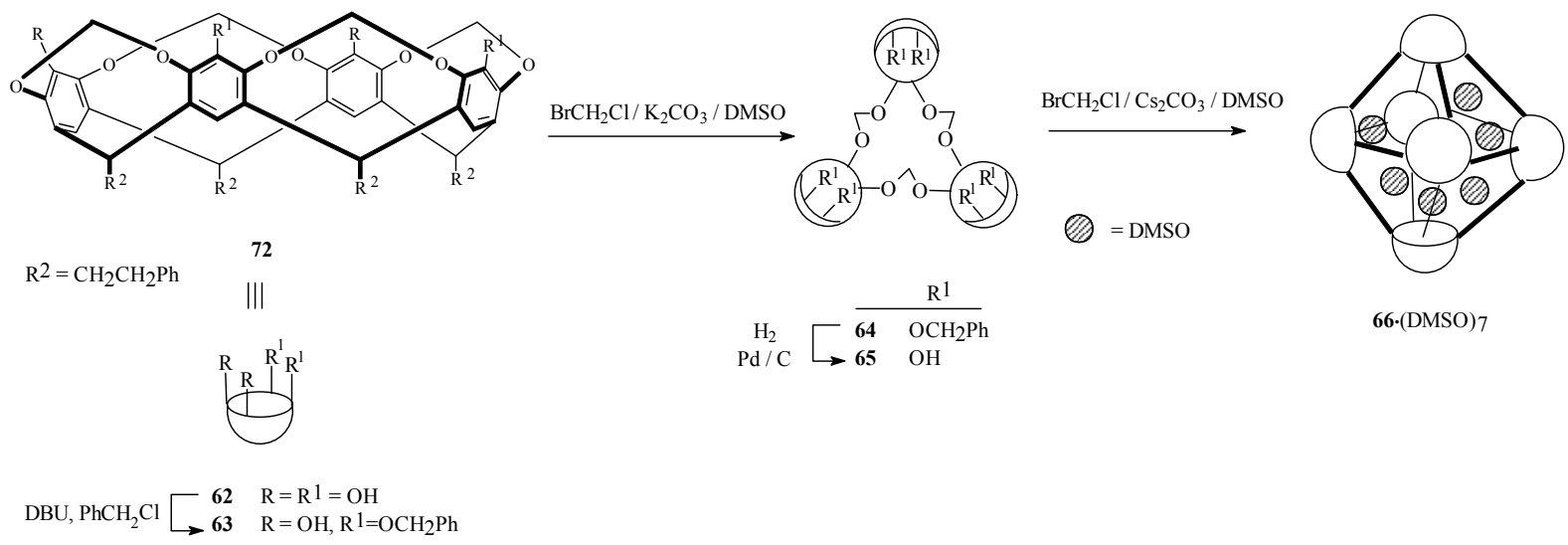



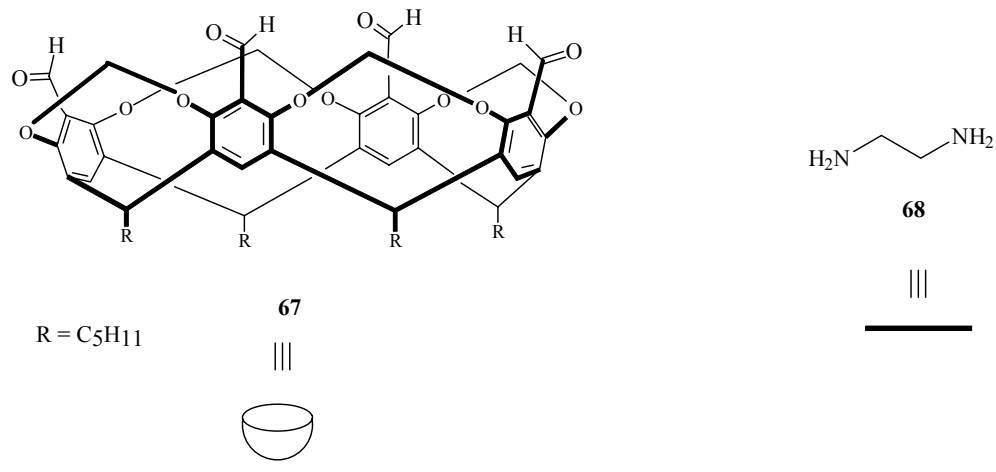

III

III
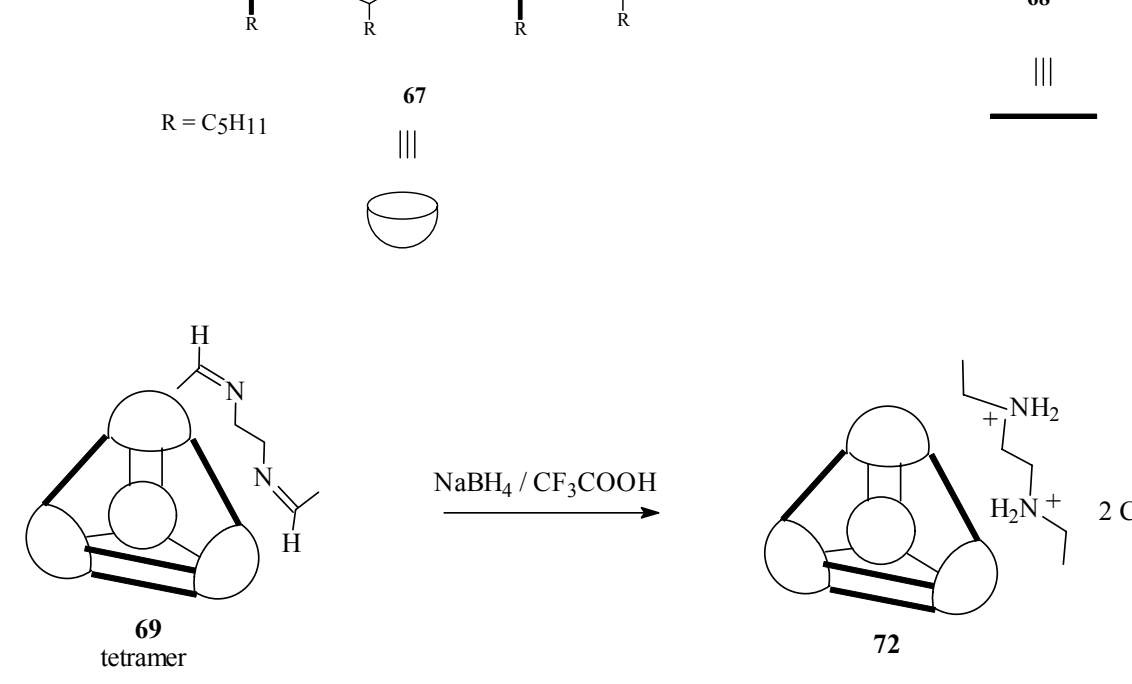

$\stackrel{\mathrm{NaBH}_{4} / \mathrm{CF}_{3} \mathrm{COOH}}{\longrightarrow}$

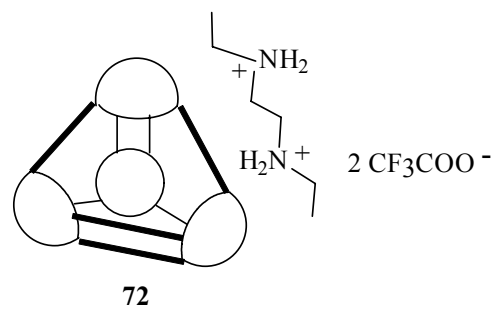

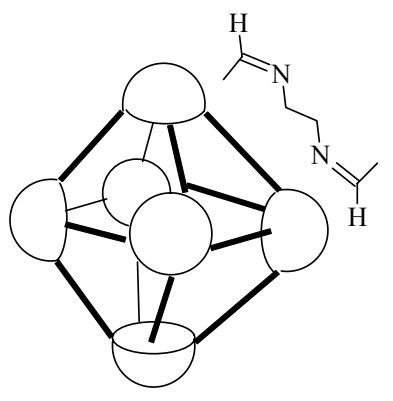

70 hexamer

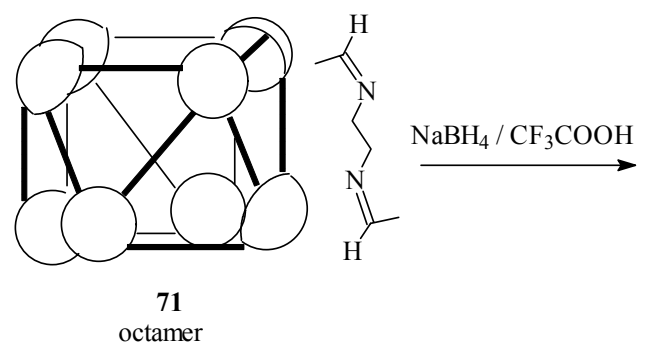

$\stackrel{\mathrm{NaBH}_{4} / \mathrm{CF}_{3} \mathrm{COOH}}{\longrightarrow}$

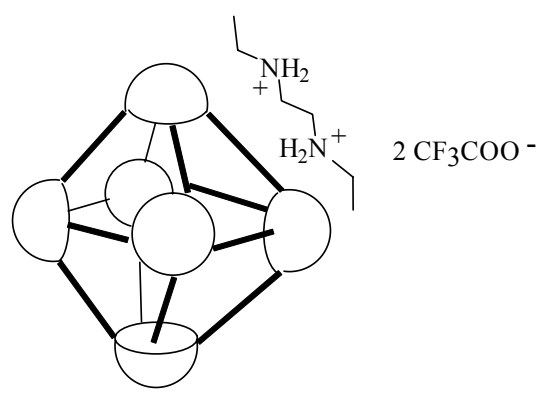

73

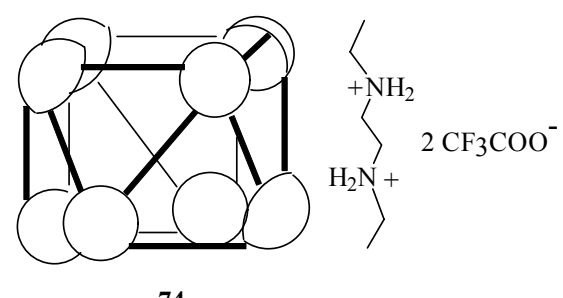

74

\section{Scheme 9}

It should be noted that linear oligomers or $2 \mathrm{D}$ sheets are not formed. ${ }^{65,66}$ Reduction of all imine bonds in 69-71 with $\mathrm{NaBH}_{4}$ in the presence of trifluoroacetic acid yields covalently bound capsules 72-74, respectively, isolated as trifluoroacetate salts. 


\section{Conclusions}

In this article selected examples of trimeric and hexameric calixarene-based capsules are presented. It should be pointed out that the chemistry of dimeric capsules is better known than that of capsules of higher multiplicities, this fact having its reflection in number of reports that have appeared. ${ }^{67-70}$

The above review, albeit presenting only chosen examples of trimeric and hexameric capsules highlights to some extent their formation and properties which are promising for their applications.

\section{References}

1. Liu, Y.; Huo, D.-S.; Zhang, H.-Y.; Ding, F.; Chen, K.; Song, H.-B. Chem. Eur. J. 2007, 13, 466.

2. Gibb, C. L. D.; Gibb, B. C. Chem. Commun. 2007, 1635.

3. Leontiev, A. V.; Saleh, A. W.; Rudkevich, D. M. Org. Lett. 2007, 9, 1753.

4. Kobyayashi, K.; Kitagawa, R.; Yamada, Y.; Yamanaka, M.; Suematsu, Y.; Sei, Y.; Yamaguchi, K. J. Org. Chem. 2007, 72, 3242.

5. Vatsouro, I.; Rudzevich, V.; Böhmer, V. Org. Lett. 2007, 9, 1375.

6. Kerckhoffs, J. M. C. A.; Mateos-Timoneda, M. A.; Reinhoudt, D. N.; Crego-Calama, M. Chem. Eur. J. 2007, 13, 2377.

7. Stirling, C. J. M.; Fundin, L. J.; Williams, N. H. Chem. Commun. 2007, 1748.

8. Dalgarno, S. J.; Power, N. P.; Antesberger, J.; McKinlay, R. M.; Atwood, J. L. Chem. Commun. 2006, 3803.

9. Ajami, D.; Schramm, M. P.; Volonterio, A.; Rebek, J.,Jr. Angew. Chem. Int. Ed. 2007, 46, 242

10. Liu, X.; Warmuth, R. J. Am. Chem. Soc. 2006, 128, 14120.

11. Liu, X.; Liu, Y.; Li, G.; Warmuth, R. Angew. Chem. Int. Ed. 2006, 45, 901.

12. Organo, V. G.; Sgarlata, V.; Firouzbakht, F.; Rudkevich, D. M. Chem. Eur. J. 2007, 13, 4014.

13. Gottschalk, T.; Jaun, B.; Diederich, F. Angew. Chem. Int. Ed. 2007, 46, 260.

14. Śliwa, W. Arkivoc 2006, V,137.

15. Śliwa, W.; Peszke, J. Minireviews in Organic Chemistry 2007, 4, 125.

16. Śliwa, W.; Matusiak, G.; Deska, M. Heterocycles 2002, 57, 2179.

17. Śliwa, W.; Deska, M. Khim. Get. Soedin. 2002, 740.

18. Śliwa, W. J. Inclusion Phenom. Macrocycl. Chem. 2005, 52, 13.

19. Śliwa, W. Croat. Chem. Acta 2002, 75, 131.

20. Śliwa, W.; Zujewska, T.; Bachowska, B. Polish J. Chem. 2003, 77, 1079.

21. Śliwa, W. Heterocycles 2002, 57, 169

22. Ugono, O.; Holman, K. T. Chem. Comunn. 2006, 2144. 
23. Rissanen, K. Angew. Chem. Int. Ed. 2005, 44, 3652.

24. Makeiff, D. A.; Sherman, J. C. J. Am. Chem. Soc. 2005, 127, 12363.

25. Fujita, M.; Tominaga, M.; Hori, A.; Therrien, B. Acc. Chem. Res. 2005, 38, 369

26. Rebek, J.,Jr. Angew. Chem. Int. Ed. 2005, 44, 2068.

27. Lützen, A. Angew. Chem. Int. Ed. 2005, 44, 1000.

28. Liu, X.; Chu. G.; Moss, R. A.; Sauers, R. R.; Warmuth, R. Angew. Chem. Int. Ed. 2005, 44, 1994.

29. Yoshizawa, M.; Kumazawa, K.; Fujita, M. J. Am. Chem. Soc. 2005, 127, 13456.

30. Mough, S. T.; Goeltz, J. C.; Holman, K. T. Angew. Chem. Int. Ed. 2004, 43, 5631.

31. Menozzi, E.; Pinalli, R.; Speets, E. A.; Ravoo, B. J.; Dalcanale, E.; Reinhoudt, D. N. Chem. Eur. J. 2004, 10, 2199.

32. ten Cate, M. G. J.; Omerović, M., Oshovsky, G.V.; Crego-Calama, M.; Reinhoudt, D. N. Org. Biomol. Chem., 2005, 3, 3727.

33. Percec, V.; Peterca, M.; Sienkowska, M. J.; Ilies, M. A.; Aqad, E.; Smidrkal, J.; Heiney, P. A. J. Am. Chem. Soc. 2006, 128, 3324.

34. Piermattei, A.; Giesbers, M.; Marcelis, A. T. M.; Mendes, E.; Picken, S. J.; Crego-Calama, M.; Reinhoudt, D. N. Angew. Chem. Int. Ed. 2006, 45, 7543.

35. ten Cate, M. G. J.; Reinhoudt, D. N.; Crego-Calama, M. J. Org. Chem. 2005, 70, 8443.

36. Kerckohoffs, J. M. C. A.; ten Cate, M. G. J.; Mateos-Timoneda, M. A.; van Leeuwen, F. W. B.; Snellink-Ruël, B.; Spek, A. L.; Kooijman, H.; Crego-Calama, M.; Reinhoudt, D. N. J. Am. Chem. Soc. 2005, 127, 12697.

37. Mateos-Timoneda, M. A.; Crego-Calama, M.; Reinhoudt, D. N. Chem. Eur. J. 2006, 12, 2630.

38. Mateos-Timoneda, M. A.; Crego-Calama, M.; Reinhoudt, D. N. Supramol.Chem. 2005, 17, 67.

39. Mateos-Timoneda, M. A.; Kerckhoffs, J. M. C. A.; Reinhoudt, D. N.; Crego-Calama, M. Org. Biomol. Chem. 2007, 5, 447.

40. Schweiger, M.; Yamamoto, T.; Stang, P. J.; Blaser, D.; Boese, R. J. Org. Chem. 2005, 70, 4861.

41. 41. Fiedler, D.; Leung, D. H.; Bergman, R. G.; Raymond, K. N. Acc. Chem. Res. 2005, 38, 349.

42. Argent, S. P.; Riis-Johannessen, T.; Jeffery, J. C.; Harding, L. P.; Ward, M. D. Chem Commun. 2005, 4647.

43. Yamanaka, M.; Yamada, Y.; Sei, Y.; Yamaguchi, K.; Kobayashi, K. J. Am. Chem. Soc. 2006, 128, 1531.

44. Haino, T.; Kobayashi, M.; Chikaraishi, M.; Fukazawa, Y. Chem. Commun. 2005, 2321.

45. Zuccaccia, D.; Pirondini, L.; Pinalli, R.; Dalcanale, E.; Macchioni, A. J. Am. Chem. Soc. 2005, 127, 7025.

46. Jude, H.; Sinclair, D. J.; Das, N.; Sherburn, M. S.; Stang, P. J. Org. Chem. 2006, 71, 4155. 
47. Fox, O. D.; Cookson, J.; Wilkinson, E. J. S.; Drew, M. G. B.; MacLean, E. J.; Teat, S. J.; Beer, P. D. J. Am. Chem. Soc. 2006, 128, 6990.

48. Palmer, L. C.; Rebek, J.,Jr. Org. Lett. 2005, 7, 787.

49. Avram, L.; Cohen, Y. J. Am. Chem. Soc. 2005, 127, 5714.

50. Dalgarno, S. J.; Tucker, S. A.; Bassil, D. B.; Atwood, J. L. Science 2005, 309, 2037.

51. Cohen, Y.; Avram, L.; Frish, L. Angew. Chem. Int. Ed. 2005, 44, 520.

52. Avram, L.; Cohen, Y. Org. Lett. 2006, 8, 219.

53. Yamanaka, M.; Shivanyuk, A.; Rebek, J.,Jr. J. Am. Chem. Soc. 2004, 126, 2939.

54. Palmer, L. C.; Shivanyuk, A.; Yamanaka, M.; Rebek, J.,Jr. Chem. Commun. 2005, 857.

55. Ugono, O.; Holman, K. T. Chem. Commun. 2006, 2144.

56. Antesberger, J.; Cave, G. W. V.; Ferrarelli, M. C.; Heaven, M. W.; Raston, C. L.; Atwood, J. L. Chem. Commun. 2005, 892.

57. Dalgarno, S. J.; Bassil, D. B.; Tucker, S. A.; Atwood, J. L. Angew. Chem. Int. Ed. 2006, 45, 7019.

58. Beyeh, N. K.; Kogej, M.; Ahman, A.; Rissanen, K.; Schalley, C. A. Angew. Chem. Int. Ed. 2006, 45, 5214.

59. McKinlay, R. M.; Cave, G. W. V.; Atwood, J. L. PNAS, 2005, 102, 5944.

60. McKinlay, R. M.; Thallapally, P. K.; Cave, G. W. V.; Atwood, J. L. Angew. Chem. Int. Ed. 2005, 44, 5733.

61. Leung, K. C.-F.; Arico, F.; Cantrill, S. J.; Stoddart, J. F. J. Am. Chem. Soc. 2005, 127, 5808.

62. West, K. R.; Bake, K. D.; Otto, S. Org.Lett. 2005, 7, 2615.

63. Lam, R. T. S.; Belenguer, A.; Roberts, S. L.; Naumann, C.; Jarrosson, T.; Otto, S.; Sanders, J. K. M. Science 2005, 308, 667.

64. Makeiff, D. A.; Sherman, J. C. J. Am. Chem. Soc. 2005, 127, 12363.

65. Kamplain, J. W.; Bielawski, C. W. Chem. Commun. 2006, 1727.

66. González-Álvarez, A.; Alfonso, I.; Gotor, V. Chem. Commun. 2006, 2224.

67. Salvio, R.; Moisan, L.; Ajami, D.; Rebek, J.,Jr. Eur. J. Org. Chem. 2007, 2722.

68. Dalgarno, S. J.; Thallapally, P. K.; Barbour, L. J.; Atwood, J. L. Chem. Soc. Rev. 2007, 36, 236.

69. Oshovsky, G.V.; Reinhoudt, D. N.; Verboom, W. Angew. Chem. Int. Ed. 2007, 46, 2366.

70. Baldini, L.; Casnati, A.; Sansone, F.; Ungaro, R. Chem. Soc. Rev. 2007, 36, 254. 


\section{Authors' biographical data}

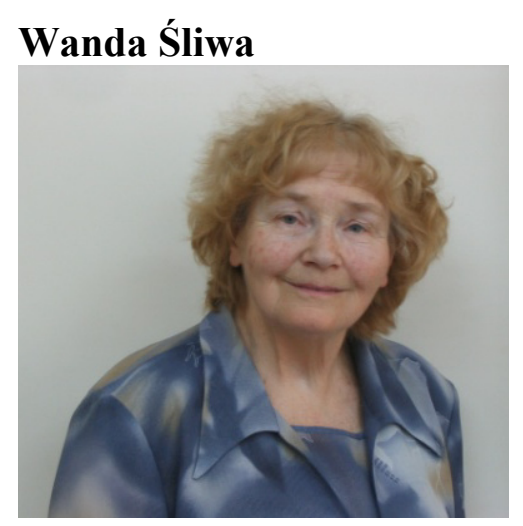

Wanda Śliwa graduated from Wrocław Polytechnical University, Poland, she received there her M.Sc. and Ph.D. degrees. She worked at this University as an Assistant Professor, and then as an Associate Professor. After a year of research (1973/74) at Université Paul Sabatier à Toulouse, France, she moved to Jan Długosz University (formerly Pedagogical University) of Częstochowa, Poland. She is Professor of Chemistry since 1990, has been a Vice-Rector, a Head of Organic Chemistry Department and Director of Institute of Chemistry at this University. She works at the Institute of Chemistry and Environmental Protection of Jan Długosz University of Częstochowa, her research interests concern azaaromatic compounds and supramolecular chemistry.

\section{Barbara Dondela}

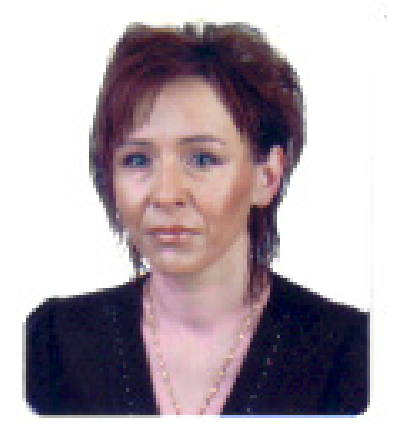

Barbara Dondela graduated from Pedagogical University of Częstochowa, Poland, she received there M.Sc. degree in 1995. Since this time she works at Jan Długosz University (formerly Pedagogical University) of Częstochowa in Organic Chemistry Department. In 2002 she obtained the Sc.D. at Jagiellonian University of Krakow, her doctoral thesis concerned physicochemical properties of diazaphenanthrenes. The research interests of Dr Barbara Dondela are connected with chemistry of heterocyclic compounds. 